\title{
FIRST ANNOUNCEMENT
}

SECOND INTERNATIONAL SYMPOSIUM ON DRYING

July 7-9, 1980

\author{
McGill University \\ Montreal, Canada
}

Papers are invited on all aspects of drying with special emphasis on industrial practice and industrial applications of theory and modeling. Sessions planned include: simulation, transport processes in drying, drying of paper and related products, drying of foodstuffs, drying of grains, energy considerations, spray drying and atomization, solar drying, industrial drying systems, drying of gases and liquids, etc. Abstracts in triplicate required before September 30, 1979 and camera-ready final manuscripts of accepted papers by December 15, 1979. A set of bound Proceedings will be published. Contact

\author{
Dr. A. S. Mujumdar, Program Chairman \\ Department of Chemical Engineering \\ McGill University \\ 3480 University Street \\ Montreal, Quebec, Canada \\ H3A 2 A7
}

